\title{
Contribuição para a Aprendizagem Transdisciplinar do Químico
}

Tibor Rabóczkay*

Instituto de Química da Universidade de São Paulo

* Autor para correspondência: trabocka@iq.usp.br

\section{RESUMO}

É descrita uma proposta de disciplina de graduação para o Instituto de Química da USP, visando à integração dos conhecimentos adquiridos pelos estudantes nas diversas áreas da Química e à melhor preparação para a realidade cotidiana da profissão. Os trabalhos seriam desenvolvidos com o modelo de uma cidade hipotética, porém, com características reais de problemas pertinentes à atividade do profissional de Química. São discutidas, brevemente, a necessidade de disciplinas de natureza aplicada e a resistência geral a inovações reais no ensino.

Palavras-chave: Educação Química; Educação para a Profissão; Integração do Conhecimento; Aprendizado com Problemas Reais.

\begin{abstract}
A proposal of an undergraduate course to the Instituto de Química da USP to integrate the knowledge acquired by students in the different fields of chemistry and the best preparation for the everyday reality of the profession is described. The study would be developed with the model of a hypothetical town, however with actual issues pertaining to the chemistry professional activity. The need of such integrating courses and the general resistance to actual innovations in education are briefly discussed.
\end{abstract}

Keywords: Education in Chemistry; Education for the Profession; Integration of Knowledge; Learning with Real Problems.

\section{O Problema}

A aprovação num exame vestibular representa na vida do jovem estudante não uma etapa de um processo contínuo, mas um rompimento desconcertante. Em curto lapso de tempo, ele ou ela sai da segurança de um grupo social relativamente pequeno, em que desempenha um papel bem definido, de hábitos seguros e valores conhecidos, para se encontrar num novo grupo muito heterogêneo em seus valores, em conhecimento e em suas origens. $\mathrm{O}$ ingressante, nas novas circunstâncias, vê-se exposto a maneiras de ver a vida, a concepções diferentes e novas. Por exemplo, um jovem despolitizado de repente se encontra diante de outros jovens, de camadas sociais diversas e altamente politizados, possivelmente antagônicos aos valores aprendidos e assimilados em sua família e em seu meio social de origem. Outra fonte de espanto é a melhor qualidade dos professores universitários em comparação com os do ciclo anterior ou dos cursinhos. Enquanto estes treinam, ou programam, com muito talento didático, para resolver questões de vestibular, aqueles têm por tarefa ensinar a pensar. Ensinam a pensar em geral (poucos) e/ou ensinam a pensar dentro dos limites da matéria que lecionam (a maioria) -, frequentemente com o interesse pelo conhecimento superando em larga medida a habilidade didática. As respostas certas no final da apostila, confirmadas pelo professor do colégio ou do cursinho, passam a ser substituídas, na faculdade, pela incerteza e a responsabilidade pessoal. Nota-se que, além da semana de recepção dos calouros - plena de brincadeiras -, devota-se pouca atenção ou esforço para a adaptação dos ingressantes à nova situação. A maioria dos docentes e pesquisadores 
tende até a ignorar o impacto psicológico dessa mudança, ocorrida em poucos dias, na vida do estudante: num momento, o ainda "sapinho" do cursinho, ao beijo do destino, quase instantaneamente se transforma em príncipe ou princesa do almejado ensino superior.

\section{O Problema Específico}

A imagem pública da Química é desfavorável e falsa. Contrariamente à Física, que, após a aquisição de alguns conceitos, já permite ilustrações, exemplos do cotidiano e exercícios, relativamente simples e interessantes, o raciocínio químico requer conhecimentos memorizados. Por outro lado, a matéria é associada pelos leigos a eventos negativos como a poluição e a contaminação ambiental, de alimentos etc. Daí surgirem anúncios do tipo "alface sem química", "alimentos orgânicos" ou "naturais" e outras expressões de semelhantes significados. Os ingressantes podem ficar surpresos com disciplinas como a Termodinâmica, Cinética Química, Estrutura, Quimiometria etc., que implicam cálculos sofisticados. Passados os dias de festa, os estudantes enfrentam imediatamente disciplinas específicas de Química, conforme a grade, cujo rearranjo circular, de tempos em tempos, se origina nas idiossincrasias dos componentes da Comissão de Graduação da ocasião - comissão sempre presa ao sistema semestral -, sem uma inovação verdadeira e significativa. Não há preocupação nem com a adaptação do estudante, nem com a interação entre as disciplinas e a integração do conhecimento.

$\mathrm{Na}$ falta de uma orientação coletiva ou institucional, os professores e professoras tentam o impossível: adaptarem-se a um número grande de alunos de índoles diversas, assumindo uma atitude de tolerância diante do comportamento muitas vezes inadequado, nas salas de aula e laboratórios, e de lenidade em relação ao conhecimento adquirido - imperfeito e estanque. Evidentemente, contribui para tanto a pedagogia tolerante, em voga nas últimas décadas, que procura não "traumatizar" o aprendiz. Ele e ela são tratados como coitadinhos, num proceder que denomino "amadrinhamento".

\section{As Consequências}

Observamos duas consequências da situação descrita. Em primeiro lugar, o aluno terá de realizar um esforço grande, e sob a pressão do tempo, uma vez formado e empregado, para resolver problemas que cabem a sua profissão. Precisará aprender a unir os conhecimentos adquiridos que permaneceram estanques em sua mente, e deverá aprender a agir e a reagir às situações que o setor produtivo, ou de ensino, se por este optar, lhe apresentará. Em segundo lugar e agravando o primeiro problema, o "amadrinhamento" prejudica o amadurecimento psicológico e profissional. Consequentemente, ocorrem situações caricatas como o recém-formado ir a uma entrevista de emprego vestindo bermuda e chinelos - ou acompanhado de um dos genitores ou de ambos. Tais ocorrências acabam prejudicando não só o candidato, mas também a imagem da instituição em que se formou.

\section{À Procura da Solução}

A remediação, em nossa perspectiva, inicia-se com a criação de algumas disciplinas novas - em vez da ciranda-cirandinha da grade curricular -, de adaptação dos ingressantes e de formação daqueles que devem ser considerados, na realidade, pré-profissionais. Pré-profissionais, visto que, dentro de alguns anos, se verão encarregados de tarefas importantes que implicarão produtividade industrial, questões financeiras, questões de segurança e, eventualmente, a liderança de equipes. Aos ingressantes, a adaptação ao sistema universitário; aos pré-profissionais, a adaptação à profissão, com o desenvolvimento da habilidade de empregarem de forma integrada o conhecimento adquirido nas diferentes disciplinas, quando lhes couberem as tarefas profissionais.

Com esses objetivos em mente, propusemos no IQ-USP a disciplina de graduação Integrando o Conhecimento Químico.

A disciplina se baseia em problemas e em eventuais projetos de desenvolvimento de um município virtual, mas com contornos de realidade. Obviamente, o ponto de partida pode ser um município real. A busca de tais espaços já abre a janela para o mundo profissional real, e, antes de 
enfrentarem problemas "reais", os alunos já participariam de toda a dinâmica a eles relacionada. Assim, alguns podem ser adicionados em função de uma discussão preliminar com a classe ou, mesmo, no decorrer do semestre, com base em noticiários, o que favorece o treinamento para enfrentar imprevistos.

A classe seria dividida em grupos de quatro a cinco alunos que, conforme as próprias decisões, atuariam competindo ou colaborando entre si, simulando o atendimento de consultas de autoridades e empresários, visando a obter um ou mais supostos contratos.

Nessa fase inicial, os participantes já aprenderiam um pouco de teoria da tomada de decisões e a aplicariam. Entre os desafios iniciais poderão figurar: (1) a poluição de um rio usado para (2) captação de água; (3) a poluição atmosférica; (4) chuva ácida; (5) a proteção de estruturas, monumentos e edifícios; (6) outros tipos de contaminação ambiental, como o uso de agrotóxicos etc. Poderiam ser aí incluídos aspectos de higiene de trabalho, ecologia industrial etc.

Assuntos "novos", na qualidade de imprevistos, com base no noticiário, seriam acidentes químicos, desastres na indústria química, incêndio em plantas industriais, oportunidades comerciais etc.

$\mathrm{Na}$ solução dessas questões, mantida evidentemente a escala, o estudante de Química aprende a usar integradamente seus conhecimentos adquiridos em disciplinas diversas (conhecimentos químicos e outros, como os estatísticos). Eventualmente, os grupos poderão apresentar propostas para incrementar a vida econômica do município com base em suas características (características reais do município tomado por modelo ou fictícias): (1) introdução de alguma indústria; (2) criação de um curso técnico médio ou superior; (3) aproveitamento de resíduos, reciclagem etc., sempre com o uso de recursos como o brainstorming.

Finalmente, o aluno treina a elaboração de propostas e de relatórios; além de trabalhos de caráter científico, produz materiais adequados para o entendimento por: administradores públicos, administradores do setor privado, engenheiros e técnicos e, possivelmente, a sociedade e a mídia - isto é, o aluno desenvolve a comunicação com setores diversos.

\section{Destino da Proposta}

O Conselho do Departamento solicitou parecer sobre a proposta à Comissão de Graduação, que por ora, não acolheu a inclusão da disciplina na grade de obrigatórias. Como alternativa, propusemos que esta fosse ministrada em nível de pós-graduação. Sendo a preocupação dos alunos de mestrado e doutorado de natureza mais específica, o sucesso foi limitado. Uma outra possibilidade reside na atração de interessados em disciplina optativa. Tal esforço encontra respaldo na verificação, posterior à apresentação realizada no Congresso de Graduação da Universidade de São Paulo $^{1}$, de que semelhantes preocupações estão se manifestando em outras universidades, especialmente em instituições americanas.

\section{Nota}

$1<$ http://www.congressograduacao.usp.br/i-congresso/>

\section{Referências Bibliográficas}

AMERICAN Chemical Society. Chemistry in the Community. 6. ed. Dubuque: Kendall/Hunt, 2011.

ASHRAF, S. Salman; MARZOUK, Sayed A. M.; SHEHADI, Ihsan A.; MURPHY, Brian M. "An Integrated Professional and Transferable Skills Course for Undergraduate Chemistry Students". 7. Chem. Educ., vol. 88, n. 1, 2011, pp. 44-48.

GIANNETTI, Biagio Fernando \& ALMEIDA, Cecília Maria Villas Bôas de. Ecologia Industrial: Conceitos, Ferramentas e Aplicações. São Paulo: Edgard Blücher, 2006.

JONES, Mary Lou Baker \& SEYBOLD, Paul G. "Combining Chemical Information Literacy, Communication Skills, Career Preparation, Ethics, and Peer Review in a Team-Taught Chemistry Course". F. Chem. $E d$., vol. 93, n. 3, 2016, pp. 439-443.

MANAHAN, Stanley E. Industrial Ecology: Environmental Chemistry and Hazardous Waste. Washington: Lewis, 1999.

TUCAI, Valerie K.; O'CONNOR, Abby R.; BRADLEY, Lynn M. "A Three-Year Chemistry Seminar Program Focusing on Career Development Skills". 7. Chem. Educ., vol. 91, n. 12, 2014, pp. 2071-2077. 